\title{
Rehunkorjuumenetelmien vertailu peltolohkojen etäisyyden kasvaessa
}

\author{
Janne Räisänen ${ }^{1}$, Pasi Eskelinen ${ }^{2}$, Jarkko Partanen ${ }^{2}$ \\ 1. Savonia-amk, PL 1000, 78211 Varkaus, etunimi.sukunimi@savonia.fi \\ 2. Savonia-amk, PL 72, 74101 Iisalmi, etunimi.sukunimi@savonia.fi
}

\section{Tiivistelmä}

Rehulogistiikan kehittäminen karjatiloille -hankkeessa (REKKA) selvitetään peltojen etäisyydestä johtuvia logistisia kustannuksia ja niiden vaikutusta rehuntuotannon kannattavuuteen. Osana rehuntuotannon kannattavuusvertailuja valmisteltiin laskureita säilörehun korjuumenetelmien vertailemiseksi ja kuljetusmatkan vaikutuksen selvittämiseksi. Keskeiset vertailumenetelmät olivat säilörehun pyöröpaalaus, noukinvaunukorjuu sekä (ajo)silppurikorjuu. Koska karjatilojen rehunkorjuuseen liittyy myös lannan siirto ja levitys, sen kustannus- ja hyötytekijät otettiin vertailuun omalla laskurillaan.

Tutkimusosion tarkoituksena oli selvittää erityisesti kaukana $(10-50 \mathrm{~km})$ sijaitsevien peltojen rehuntuotannon kustannuksia ja työhön kuluvaa aikaa. Laajentavien karjatilojen lisääntyvä peltoala sijaitsee yleensä entisiä peltoja kauempana. Näiden kustannusten selvittäminen antaa mahdollisuuksia tarkastella uusien investointien kannattavuutta ja takaisinmaksuaikaa. Laajentavilla tiloilla myös ajankäytön vaatimukset muuttuvat ja aiemmin käytössä olleilla menetelmillä korjuuaika kasvaa liian suureksi. Rehun laadullisten tekijöiden varmistamiseksi korjuutyöhön on usein pakko ottaa käyttöön tehokkaampia menetelmiä.

Vertailulaskureiden kehittämisessä pyrittiin ottamaan huomioon rehunkorjuun keskeiset muuttujat. Rehunkorjuumenetelmien vertailulaskurissa keskitytään menetelmien välisiin koneketjujen eroihin ja kuljetusajan laskurilla irtorehun ja pyöröpaalien kuljetuksen tehostamiseen etäisyyden kasvaessa. Lannan kuljetusajan laskuri on otettava osaksi tarkastelua, koska karjatilan on pystyttävä sijoittamaan lanta käytössä oleville pelloilleen. Pitkillä kuljetusmatkoilla oli ennakoitavissa, että tehoton lannan kuljetus rasittaa rehuntuotannon kannattavuutta. Toisaalta tilan käytettävissä oleva työajan ja työvoiman riittävyys voivat tulla rajoittavaksi tekijäksi.

Kannattavuuslaskureissa keskeisin kannattavuuteen vaikuttava tekijä perustui pellon etäisyyden vaikutukseen. Etäisyyttä tarkasteltiin erityisesti ajonopeuden, kuormakoon ja ajankäytön näkökulmista. Kustannusten kannalta käytettävä kokonaistyöaika on merkittävä tekijä. Ajankäytön kustannusten vertailemiseksi laskureihin voi syöttää omat tavoitekustannukset tai urakoitsijahinnat. Lannanlevityslaskurissa voi hyödyntää karjanlannan ravinneanalyysin tietoja, jolloin työn kustannuksia voi verrata lannoituksella saatuun hyötyyn.

Vertailulaskureiden tuloksia vertailtiin esimerkkitilojen eri vaihtoehtoihin. Suurimmiksi tekijöiksi työn tehostamiseksi nousivat kuormakoon kasvattaminen ja keskinopeus. Molemmilla tekijöillä tulee vastaan käytännön rajoitukset, jolloin logistiikan tehostamisessa on keskityttävä pienempien työvaiheiden järjestelmälliseen nopeuttamiseen. Tämä todentui erityisesti pyöröpaalien käsittelyssä ja lannan kuormausajassa. Laskureilla voidaan myös simuloida traktoreiden ja kuorma-autojen eroja kuljetustehokkuudessa ja samalla voidaan tarkastella urakoitsijoiden palkkaamisen kannattavuutta.

\author{
ASIASANAT \\ Logistiikka, rehunkorjuumenetelmät, työajankäyttö, karjanlannan siirto
}




\section{Johdanto}

Säilörehunkorjuu on karjatilojen tärkein rehuraaka-aineen käsittelyprosessi. Korjuu on aikasidonnainen säilörehun laadun vuoksi. Kasvuaste ja korjuusää ohjaavat korjuuta. Korjuumenetelmä joudutaan valitsemaan siten, että sato ennätetään korjaamaan ilman suurta riskiä sääolosuhteiden tai kasvuasteen aiheuttamista tappioista.

Karjatilojen jatkuvan kasvun vuoksi säilörehun korjuuala suurenee. Kertaluokkainen korjuualan kasvu on usein 50 - $100 \%$. Lisääntyvä korjuuala on samalla yhä kauempana tilakeskuksesta. Lisääntyvästä kuljetusmatkasta voi tulla korjuuketjun pullonkaula (Karttunen ym. 2004). Kasvavan tilan rehunkorjuu on uudessa tilanteessa, kun korjuuaika lisääntyy kasvaneen pinta-alan ja kuljetusmatkojen vuoksi. Tässä tutkimuksessa halutaan selvittää, miten tuotantoa kasvattava tila voi hallita peltojen etäisyyden aiheuttamat logistiset haasteet rehuntuotannossa ja lannan levityksessä. Tutkimus kuuluu Savonia AMK:n Rehulogistiikan kehittäminen karjatiloille (REKKA) -hankkeeseen.

\section{Aineisto ja menetelmät}

Lähtöaineistossa oletettiin karjatilan hankkivan lisäpeltoa 10 - 50 km etäisyydeltä tilakeskuksen ulkopuolelta. Yksi tarkastelun aihe oli, millä etäisyydellä säilörehun siirto tilakeskukseen muuttuu kannattamattomaksi. Kolme yleisintä säilörehunkorjuumenetelmää eroaa logistiikaltaan niin paljon toisistaan, että menetelmiä piti pystyä vertaamaan eri tilanteissa. Pyöröpaalauksessa paalien siirto eroaa täysin irtorehun siirrosta kalustoltaan ja aikatauluvaatimukseltaan. Noukinvaunukorjuu ja silppurikorjuu eroavat merkittävästi teholtaan ja työvoiman tarpeeltaan. Näiden kolmen menetelmän oleelliset kustannukset ja työajan tarpeet yhdisteltiin taulukkolaskennan avulla. Vertailutietoja muuttamalla voidaan nopeasti selvittää kuljetusmatkan vaikutus korjuukustannuksiin. Keskeisimmät muutettavat vertailutiedot olivat ajonopeus, kuormakoko ja kuormien täyttö- ja tyhjennysajat (korjuukoneiden teho).

Laskelmissa ei huomioitu työntutkimuksen aikalajeja kuten häiriö- ja apuaikoja. Laskureiden tarkoituksena on kuvata eri menetelmien kapasiteettia erityisesti kuljetusmatkan muuttuessa. Kustannusvertailussa käytettiin keskimääräisiä urakointihintoja (Palva 2013) vuodelta 2013 sekä suoraan urakoitsijoilta kysyttyjä veloitushintoja.

Valmiita laskureita verrattiin kolmelta tilalta saatuihin aikamittauksiin noukinvaunu-, ajosilppuri- ja pyöröpaalikorjuun osalta. Todellisista ajankäyttötuloksista keskusteltiin urakoitsijoiden sekä palvelua ostaneiden maanviljelijöiden kanssa. Paalisäilörehun kuljetuksissa mitattiin ja videoitiin tarkastelua varten myös uutta menetelmää (MPH -paalivaunu). Kyseisen vaunun prototyyppi oli käytössä yhdellä case-tilalla ja sen kokeilu ja kehitystyö avasi yksityiskohtia pyöröpaalien kuljetukseen. Rekka-autolla toteutetun pyöröpaalikuljetuksen videointi paljasti mm. kuormaustekniikoiden eroavaisuuksista johtuvia ajankäyttö- ja kustannustekijöitä. Taulukossa 1 näkyy laskelmissa käytetyt esimerkkiarvot. 
Taulukko 1: Laskelmissa käytetyt esimerkkiarvot. Lukuarvot perustuvat REKKA -hankkeen tutkimuksissa mitattuihin aikoihin (täyttö- ja tyhjennysnopeudet) sekä laskurissa käytettyihin vaihtoehtoisiin esimerkkiarvoihin.

\begin{tabular}{|c|c|c|c|c|c|c|}
\hline Korjuutapa & Pyöröpaalaus & Pyöröpaalaus & Pyöröpaalaus & Noukinvaunu & Ajosilppuri & Ajosilppuri \\
\hline Kuljetustapa & $18 \mathrm{t}$ vaunu & MPH -vaunu & Rekkakuljetus & & $10 \mathrm{t}$ vaunu & $15 \mathrm{t}$ vaunu \\
\hline satomäärä t/ha & 10 & 10 & 10 & 10 & 10 & 10 \\
\hline $\begin{array}{l}\text { Siirtonopeus, } \\
\mathrm{km} / \mathrm{h}\end{array}$ & 30 & 30 & 54 & 35 & 30 & 40 \\
\hline $\begin{array}{l}\text { Siirtovaunun } \\
\text { kuormapaino, t }\end{array}$ & 18 & 7,5 & 32 & 8 & 10 & 15 \\
\hline $\begin{array}{l}\text { Siirtovaunun } \\
\text { tyhj. nopeus, } \\
\text { min }\end{array}$ & 9 & 2 & 20 & 2 & 2 & 2 \\
\hline $\begin{array}{l}\text { Siirtovaunun } \\
\text { täyttönopeus, } \\
\text { min }\end{array}$ & 18 & 8 & 25 & 8 & 10 & 15 \\
\hline $\begin{array}{l}\text { Kuljettajan } \\
\text { palkka sivuku- } \\
\text { luineen }\end{array}$ & 25 & 25 & - & - & - & - \\
\hline $\begin{array}{l}\text { Trakt.+ vaunun } \\
\text { kust. alv } 0 \%\end{array}$ & 25 & 35 & 85 & 80 & 65 & 75 \\
\hline $\begin{array}{l}\text { Silppurin tun- } \\
\text { tikust. alv } 0 \%\end{array}$ & & & & & 300 & 300 \\
\hline $\begin{array}{l}\text { Pyöröpaalaus } \\
€ / t\end{array}$ & 5,71 & 5,71 & 5,71 & & & \\
\hline
\end{tabular}

\section{Tulokset ja tulosten tarkastelu}

Tutkimushankkeen keskeinen kysymys on, kuinka kaukaa säilörehua kannattaa siirtää lypsykarjatilalle. Tämän vuoksi ensisijaisesti tarkasteltiin, kuinka paljon kuljetusetäisyys vaikuttaa säilörehun tuotantokustannukseen eri korjuumenetelmillä. Laskureiden tavoite on, että jokainen asiasta kiinnostunut voi syöttää laskentapohjaan haluamansa arvot ja vertailla kustannuksia. Varsinkin korjuumenetelmää vaihtavien ja laajentavien tilojen tarpeisiin vertailuarvot antavat hyvän kuvan muuttuvista kustannuksista ja kokonaistyöajasta.

Hankkeen laskelmien esimerkkinä on käytetty yhden lypsyrobotin maatilan laajentumista kahden robotin käyttöön. Sen perusteella esimerkkitaulukossa kuvataan 50 hehtaarin säilörehun korjuuta eri menetelmillä karholta siiloon. Muuttuvana tekijänä on pellon (keski)etäisyys.

Peltojen etäisyyden ollessa alle $5 \mathrm{~km}$ noukinvaunulla saatiin edullisimmat siirtokustannukset. Korjuu on tehokasta pellolla, kuormasta saadaan tiivis ja kuljetuksen suhteellinen osuus työstä on alhainen. Pyöröpaalauksessa rehun kuljetuskustannus riippuu paljon kuormakoosta. Sen suuri ero muihin menetelmiin on se, että sadon voi siirtää ruokintaan rehunkorjuuajan ulkopuolella. Tässä tutkimuksessa siirtokustannus otettiin tarkasteluun siten, että kustannukset huomioidaan siirtoajankohdasta huolimatta. Kuormakoon lisäksi tärkeä tekijä on kuormausnopeus ja kuorman sidonta. Prototyyppinä testatun MPH -vaunun etu muihin menetelmiin oli selkeä lastaus, automaattinen kuorman lukitus ja nopea tyhjennys. Rekka-auton tehokkuus perustui suureen kuormauskapasiteettiin, jolloin tiekuljetusten määrä väheni. Kuorman kokoa kasvattamalla saatiin kustannussäästöä helpommin kuin ajonopeutta lisäämällä.

Ajosilppurikorjuu oli logistisesti kallein rehunkorjuutapa, mutta menetelmän sisällä on useita kustannuksiin vaikuttavia tekijöitä. Siirtonopeus vaikuttaa selkeästi silppurin toimintakapasiteettiin, sillä nopeammalla kierrolla odotusajat vähenevät. Suurempi tekijä tässäkin menetelmässä on kuormakoko. Hankkeen tutkimuksissa Maaningan koeasemalla 2013 todettiin, että siirtovaunuun mahtui hydraulisesti tiivistettynä $\mathrm{n} .50 \%$ enemmän säilörehua. Tällä menetelmällä voidaan säästää kolmasosa 
kuljetuskerroista ja menetelmä tuo tehoa ajosilppuriketjuun $3 \mathrm{~km}$ suuremmilla siirtomatkoilla. Kuvassa 1 on havainnollistettu rehunsiirtokustannusten eroja karholta karjasuojan viereen eri menetelmillä ja eri etäisyyksillä.

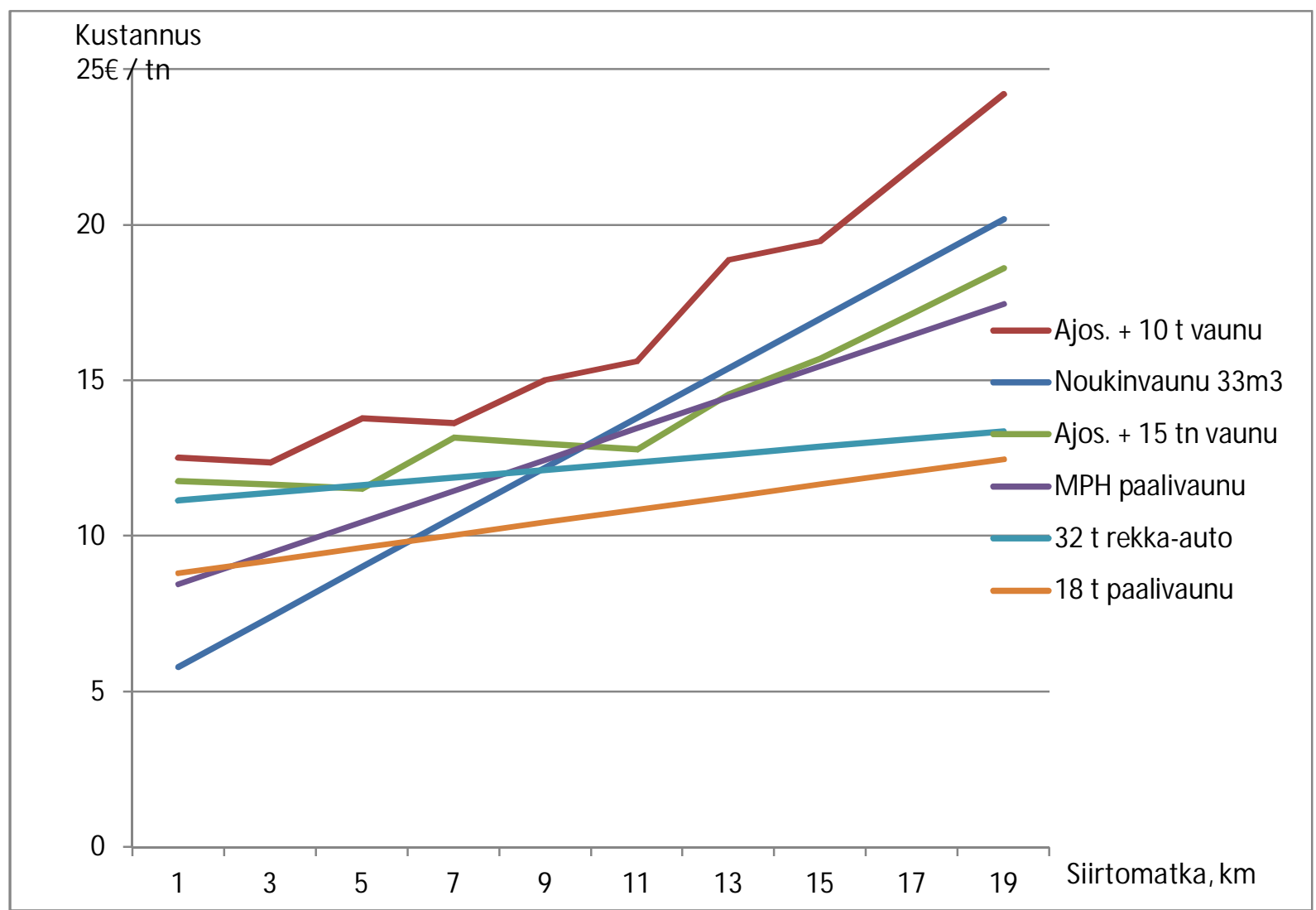

Kuva 1: Rehunsiirtokustannus karholta varastoon karjasuojan viereen eri korjuumenetelmillä

Kuvassa 2 on havainnollistettu tilannetta, jossa korjattavan säilörehualan (50 ha) korjuun kokonaisaikaa karholta varastoon on verrattu eri menetelmillä ja eri etäisyyksillä. Menetelmien eroissa on huomioitu noukinvaunu- ja ajosilppurikorjuussa siilolla tarvittava sadon tiivistysaika (18 h). Rekkaautokuljetuksessa on huomioitu pellolla tapahtuva pyöröpaalien kuljetusaika pellolta rekan kuormauspaikalle (35 paalia / h). 


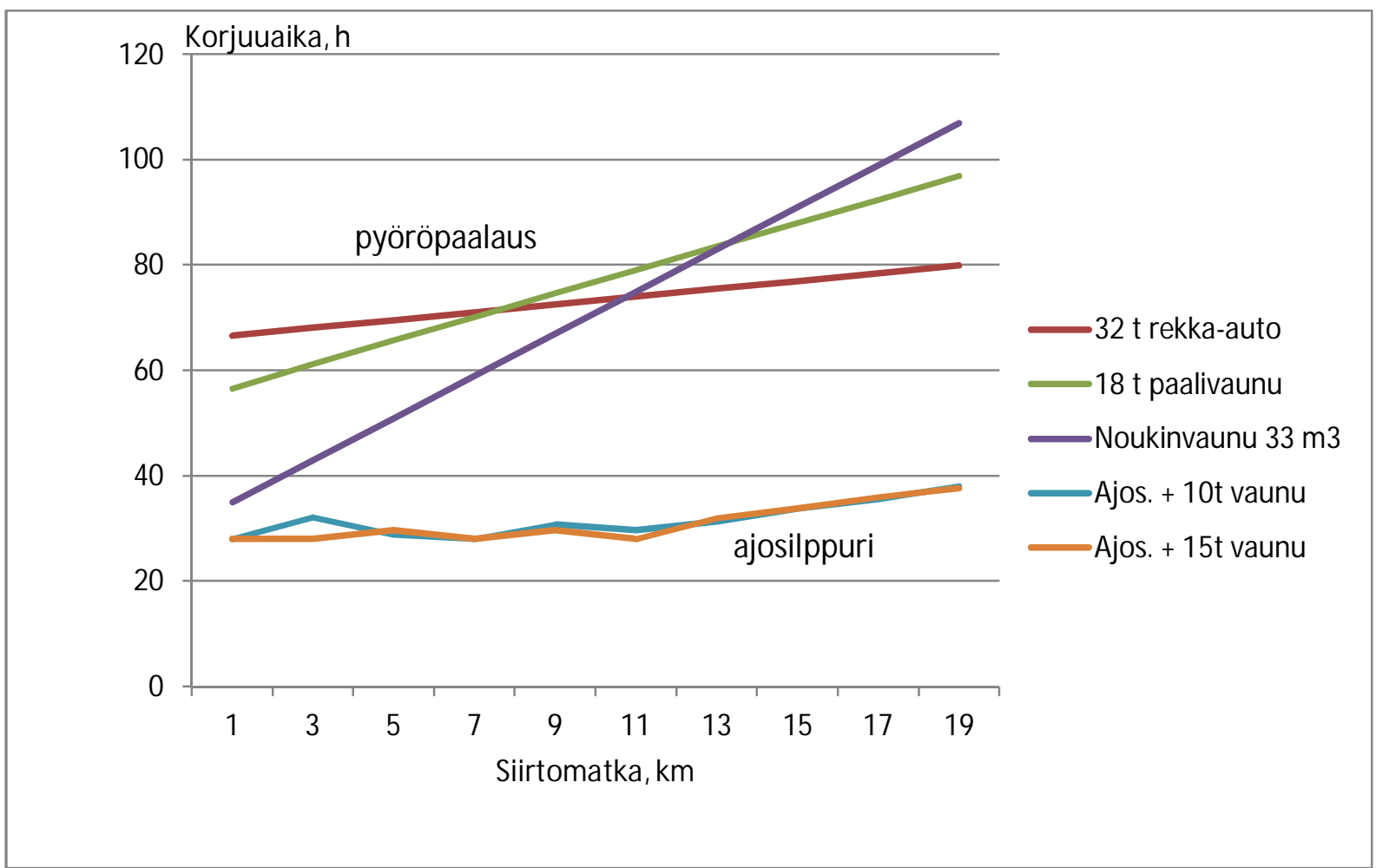

Kuva 2. 50 ha:n rehun korjuuseen kuluva kokonaisaika karholta varastoon. Noukinvaunu- ja ajosilppurityöhön sisältyy siilon tiivistysaikaa $18 \mathrm{~h}$. Rekka-autokuljetuksissa paalit on siirretty ensin traktorilla pellolta kuormauspaikalle (35 paalia/h).

\section{Johtopäätökset}

Säilörehun korjuutekniikassa logistiikan suunnittelulla ja laskennalla voidaan tehostaa tilan rehunkorjuuta ja parantaa tuotannon kannattavuutta. Tilakohtaiset erot ovat suuria ja rehunkorjuu on osatekijä koko ruokintaketjua. Tässä tutkimuksessa ei ole kyseenalaistettu rehun laadullisia tekijöitä. Useilla tiloilla työvoiman määrä ja saatavuus asettaa omat rajoitteensa korjuumenetelmän valintaan.

Kuormakoko on merkittävin rehunkorjuun tehokkuuteen ja kannattavuuteen vaikuttavista tekijöistä, kun tarkastellaan muuttujia käytännön arvojen rajoissa. Pyöröpaalien siirrossa rekkakuljetus on kustannustehokas, mutta ulkoistettuna myös suuri ajansäästö maatilalle.

Noukinvaunun suurimmat edut ovat vähäinen työvoiman ja kaluston tarve. Kuljetusmatkan kasvaessa vaunun työajasta kuluu aina suurempi osa kuljetukseen, jolloin kuljetus heikentää tehokkuutta. Noukinvaunujen kokoluokat vaikuttavat myös merkittävästi tehokkuuteen. Tässä tutkimuksessa verrattiin keskikokoluokan $\left(33 \mathrm{~m}^{3} \mathrm{DIN}\right)$ vaunua, jonka kuormapaino on 8 tonnia.

Ajosilppurikorjuu toteutetaan usein urakointityönä. Ajomatkan kasvaessa on tärkeää, että silppurin ei tarvitse odottaa siirtovaunuja. Silppurin kustannus on muihin koneisiin nähden moninkertainen joten sen jatkuva työskentely saa korjuuketjun toimimaan kannattavimmin. Rehunsiirrossa tiivistävillä vaunuilla saadaan lisää tehokkuutta heti, kun kaksi tavallista siirtovaunua ei riitä silppurin kapasiteetille.

\section{Kirjallisuus}

Palva, R. 2013. Konetyön kustannukset ja tilastolliset urakointihinnat. TTS:n tiedote: Maataloustyö ja tuottavuus 3/2013 (645)

Karttunen, J., Peltonen, M. ja Pentti, S. 2004. Säilörehun korjuuketjun suunnittelu - Rehuketjun kustannukset ja pullonkaulojen minimointi. Työte-hoseuran maataloustiedote (568) $5.8 \mathrm{~s}$. 